Howard Hughes, W. (1953). J. gen. Microbiol. 8, 307-309.

\title{
The Origin of the L-form Variants in Anaerobic Gultures of Bacterium coli
}

\author{
BY W. HOWARD HUGHES \\ The Wright-Fleming Institute, St Mary's Hospital, London, W. 2
}

SUMMARY: When a strain of Bacterium coli derived from a single cell is grown under conditions approaching anaerobiosis, three different types of cell can be demonstrated: cells which divide to give the normal colonies; $L$-form; and an intermediate type which appears normal, divides once giving two daughter cells, one of which continues to divide normally while the other becomes an L-form.

A culture of a Bacterium coli, faecal type 1 ('River Brent'), was grown on a slide by the method of Fleming, Kramer, Voureka \& Hughes (1950). Growth took place freely at room temperature, and individual organisms could be observed and photographed by phase contrast. It was noticed that a small number of the organisms failed to give normal colonies under these conditions of culture and instead grew out into so-called L-forms. See PI. 1, fig. 1.

L-form is here used in the more recent and wider sense of the term. Originally the large form of Streptobacillus moniliformis alone carried this description and in that organism $\mathbf{L}$ colonies as well as abnormal cellular units occur. Recently the term has been used to define any organism which has a similar morphology whether or not colonies occur made up entirely of these forms. The essential feature of an organism which would qualify it for inclusion as an $\mathbf{L}$ variant would be that growth continued while division was inhibited. For a discussion of this phenomenon see Pulvertaft (1952).

It was at first assumed that these $\mathbf{L}$-forms were contaminants. Single cells were therefore isolated, cultures grown from them for 3-5 hr. and the test repeated. The same appearances were noted in $3.75 \%$ of 1800 observed organisms. It appeared, therefore, that the original cell had given rise to other cells to which the environment was inimical in that division was inhibited in those organisms. Zelle \& Lederberg (1951) noted the existence of lethal variants in their cultures under rather similar conditions but do not appear to have investigated them further.

The particular factor in the environment which inhibits division in these predisposed variants was investigated. There was no association between a tendency to form excessive numbers of $\mathbf{L}$-forms on solid medium and penicillin sensitivity. The $\mathrm{pH}$ value of the medium was not responsible, nor had agar itself any action, as gelatin could be substituted for it. The degree of anaerobiosis, however, appeared to influence the result; on uncovered blocks of agar the L-forms have not been noticed. Broth cultures normally did not give L-forms with this strain but when iron strips were added then L-forms appeared. Broth cultures grown in anaerobic jars showed good L-forms 
provided they were examined immediately after removal from anaerobic conditions on to slides. As soon as there was an adequate supply of oxygen available the L-forms resumed division and gave only small forms. The type of division noticed here was the same as with penicillin-induced L-forms in the presence of penicillinase (Fleming et al. 1950), namely, the large bacillus broke down rapidly into a number of daughter cells, suggesting that cell division had been inhibited in both cases at a late stage.

In making slide cultures Brewer's medium was substituted for nutrient agar with good results, and probably the medium of choice in demonstrating the phenomenon would consist of a similar formula with rather more agar in it.

The appearances seen with the various cultures of Bact. coli 'Brent' are in no way peculiar to that strain. Other coliform organisms, including Bact. coli strain K. 12, show similar changes under anaerobic conditions. These changes are not limited to artificial culture but can be seen in direct smears of pus.

A second observation was made at the same time. The remaining apparently normal cells in the cultures divided, but nearly $17 \%$ (169 of 1000 colonies) were seen to have given rise at this stage to cells sensitive to the anaerobic conditions. The majority of cells divided into two daughter cells both of which redivided, but these aberrant cells gave two daughter cells, one of which divided normally and the other grew out without further division into an L-form. Once this L-form had been produced the normal cell associated with it divided to give a normal colony arranged alongside it, and no other $\mathbf{L}$-forms appeared in that group until the culture had become confluent and further observation was not practicable. See Pl. 1, figs. 2-6.

The L-forms could be separated from the normal small forms by the use of the micromanipulator. On transfer to broth they reverted to normal, giving cultures which, in fluid media, were indistinguishable from those of the parent strain. However, on transfer to slide cultures again the difference in susceptibility to anaerobic conditions was immediately apparent. The comparison is summarized in Table 1.

Table 1. Comparison of single cell parent-culture with subculture from a single $\mathbf{L}$-form

Strain
Brent I
L-form, $\mathrm{F}$

Immediate L-forms Immediate L-forms

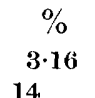

14

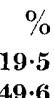

Latent L-forms Latent L-forms $\mathbf{1 9} \cdot \mathbf{5}$

$49 \cdot 6$

Subcultivation, however, showed that regression in the selected strain was taking place for, after only four or five overnight cultures, the percentages were back to the level of the parent strain. The small forms selected from slide cultures in which the L-forms had already appeared might have been assumed to give a strain which would give no more L-forms, but this was not so. While the percentages of direct L-forms fell to a fraction of $1 \%$ and it was often difficult to find any, the latent L-forms appeared in all the cultures examined. 
Journal of General Microbiology, Vol. 8, No. 2

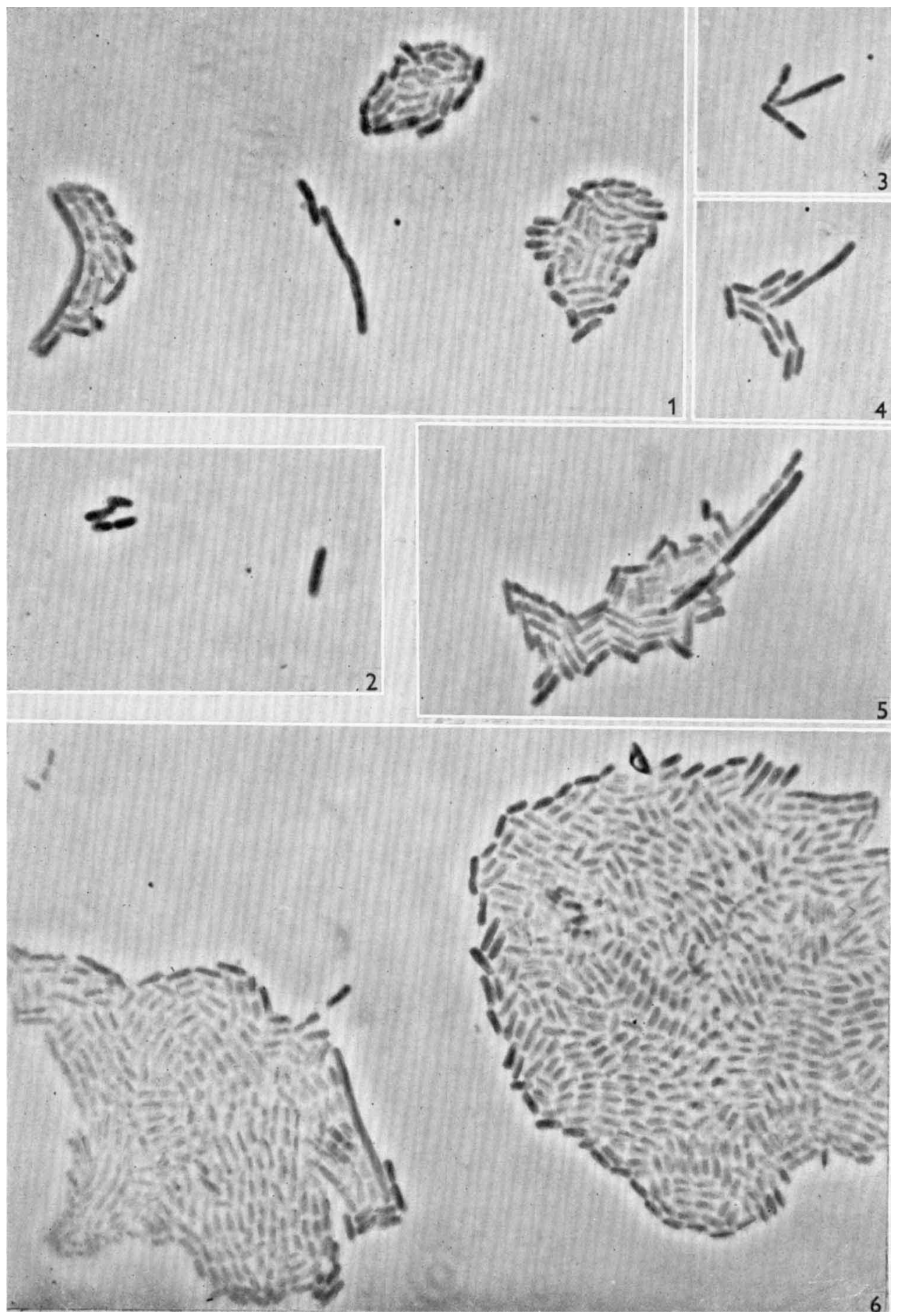

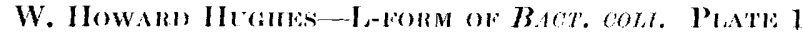




\section{REFERENCES}

Fleming, A., Voureka, A., Kramer, I. R. H., \& Hughes, W. H. (1950). The morphology and motility of Proteus vulgaris and other organisms cultured in the presence of penicillin. J. gen. Microbiol. 4, 257 .

Pulvertaft, R. J. V. (1952). The effect of antibiotics on growing cultures of Bacterium coli. J. Path. Bact. 64, 75.

Zelle, M. R. \& Lederberg, J. (1951). Single-cell isolations of diploid heterozygous Escherichia coli. J. Bact. 61, 351.

\section{EXPLANATION OF PLATE}

Original photographs by phase contrast $\times 1200$. Not all are taken from the same field but are selected as typical.

Fig. 1. The three colony types in strains grown from single cells of Bact. coli in anaerobic cultures. Left and below, normal colonies. Centre: two early L-forms developing from a pair of organisms. Right: a colony of one L-form and the progeny of one normal cell, both types arising from division of a single organism.

Fig. 2. Failure of the first division of an incipient L-form. Normal first and second divisions in sister cells.

Figs. 3-5. Development of the mixed colony from a single organism. Fig. 3. Stage of third division. Fig. 4. Stage of fifth division. Fig. 5. Stage of seventh division. The solitary L-form is now vacuolated.

Fig. 6. Later colonies, that on the left still showing an L-form at the edge, that on the right being normal.

(Received 23 September 1952) 